\title{
PYNOD reduces microglial inflammation and consequent neurotoxicity upon lipopolysaccharides stimulation
}

\author{
QI ZENG ${ }^{1}, \mathrm{CHAOFENG} \mathrm{HU}^{2}, \mathrm{RENBIN}^{2}{ }^{2}$ and DAXIANG LU ${ }^{2}$ \\ ${ }^{1}$ Department of Ultrasonic Diagnosis, The First Affiliated Hospital of Gannan Medical College, \\ Ganzhou, Jiangxi 341000; ${ }^{2}$ Key Laboratory of State Administration of Traditional Chinese Medicine of \\ The People's Republic of China, Institute of Brain Research, Department of Pathophysiology, \\ School of Medicine, Jinan University, Guangzhou, Guangdong 510632, P.R. China
}

Received May 1, 2017; Accepted March 28, 2018

DOI: $10.3892 / e t m .2018 .6108$

\begin{abstract}
PYNOD, a nod-like receptors (NLR)-like protein, was indicated to inhibit NF- $\mathrm{BB}$ activation, caspase-1-mediated interleukin (IL)-1 $\beta$ release and cell apoptosis in a dose-dependent manner. Exogenous addition of recombinant PYNOD to mixed glial cultures may suppress caspase- 1 activation and IL-1 $\beta$ secretion induced by $A \beta$. However, to the best of our knowledge, there no study has focused on the immunoregulatory effects of PYNOD specifically in microglia. The present study aimed to explore the roles of PYNOD involved in the lipopolysaccharides (LPS)-induced microglial inflammation and consequent neurotoxicity. Murine microglial BV-2 cells were transfected with pEGFP-C2-PYNOD $(0-5.0 \mu \mathrm{g} / \mathrm{ml})$ for $24 \mathrm{~h}$ and incubated with or without LPS $(1 \mu \mathrm{g} / \mathrm{ml})$ for a further $24 \mathrm{~h}$. Cell viability was determined using MTT assay and the secretion of nitric oxide (NO), IL-1 $\beta$ and caspase- 1 was measured using the Griess method or ELISA. Protein expression levels of $\mathrm{NF}-\kappa \mathrm{B}$ p 65 and inducible nitric oxide synthase (iNOS) were detected by immunofluorescent staining and/or western blot analysis. Co-culture of BV-2 cells with human neuroblastoma cell line SK-N-SH was performed in Transwell plates and the cell viability and apoptosis (using flow cytometry) of SK-N-SH cells were determined. Results indicated that PYNOD overexpression inhibited NO secretion and iNOS protein expression induced by LPS in BV-2 cells, with no detectable cytotoxicity. PYNOD overexpression also reduced the secretion of IL- $1 \beta$ and caspase- 1 from BV-2 cells upon LPS stimulation. These effects were dose-dependent.
\end{abstract}

Correspondence to: Dr Daxiang Lu, Key Laboratory of State Administration of Traditional Chinese Medicine of The People's Republic of China, Institute of Brain Research, Department of Pathophysiology, School of Medicine, Jinan University, 601 West Huangpu Avenue, Tianhe, Guangzhou, Guangdong 510632, P.R. China E-mail: zqo392@126.com

Key words: PYNOD, microglial inflammation, neurotoxicity, nitric oxide release, caspase-1-mediated IL-1 $\beta$ release, NF- $\kappa \mathrm{B}$ nuclear translocation
Additionally, PYNOD overexpression prevented LPS-induced nuclear translocation of NF- $\kappa$ B p 65 in BV-2 cells. The growth-inhibitory and apoptosis-promoting effects of BV-2 cells towards SK-N-SH cells were alleviated as a result of PYNOD overexpression. In conclusion, PYNOD may mitigate microglial inflammation and consequent neurotoxicity.

\section{Introduction}

Proteins with a nucleotide-binding oligomerization domain (NOD) and leucine-rich repeats (LRRs) are referred to as nod-like receptors (NLRs) and are involved in inflammation and apoptosis $(1,2)$. Most NLRs have critical functions in sensing pathogenic organisms or other inducers of inflammation. Indeed, Nod1 and Nod 2 promote NF- $\kappa \mathrm{B}$ activation by interacting with RICK/RIP2 (3). CARD12, NALP1, and PYPAF promote $N F-\kappa B$ activation, caspase-1-associated interleukin (IL)-1 $\beta$ synthesis, and/or apoptosis (4). On the other hand, PAN2 binds IKK $\alpha$ to reduce tumor necrosis factor (TNF) $-\alpha$ and IL-1 $\beta$-related $N F-\kappa B$ activation (5). And PYPAF3 abrogates the secretion of IL-1 $\beta$ by macrophages (6).

Recent years, several studies have reported a new NLR-like protein with anti-inflammatory effects (7), comprising pyrin domain (PYD) and NOD sequences but lacking LRRs; it was termed PYNOD (also named NLRP10 and NALP10) (8). Previous studies revealed that PYNOD binds to an adaptor protein, apoptosis-associated speck-like protein containing a CARD (ASC), and inhibits ASC-mediated NF- $\mathrm{NB}$ activation and apoptosis; PYNOD also suppresses caspase-1-mediated IL-1 $\beta$ maturation and secretion; and the effects are dose-dependent $(8,9)$. PYNOD has been shown to be essential to the functions of immunocompetent cells such as dendritic cells (10-13), macrophages and neutrophils $(8,9)$.

Microglia are immunocompetent cells of the brain and the first line effector cells responsible for immune reactions in the central nervous system (CNS) (14-16). Activation of microglia causes the secretion of multiple immune effectors, including nitric oxide (NO) via the inducible nitric oxide synthase (iNOS) and pro-inflammatory cytokines, e.g., IL-1 $\beta$, IL-6, and TNF- $\alpha$, which restore CNS homeostasis by cell and debris removal (17-19). Microglia can activate the NF- $\kappa \mathrm{B}$ pathway during neuroinflammation (20-22). Taken together, 
microglia activation results in chronic neuroinflammation and increased neuronal injury, and eventually neuronal death. The death of neurons usually follows microglia activation in multiple CNS diseases such as Alzheimer's disease (AD) (23), Parkinson's disease (PD) $(24,25)$, and amyotrophic lateral sclerosis (ALS) (26). Microglia-related neurotoxicity represents an important mechanism for neurodegeneration and reduced neuron function. Therefore, suppressing microglia induction is considered a therapeutic tool in neurodegenerative diseases (27).

A previous study showed that the degradation of PYNOD in the cytoplasm of mixed glial cells allowed the formation of the inflammasome, while exogenous addition of recombinant PYNOD to the glial cultures could reduce $A \beta$-induced caspase-1 activation and IL-1 $\beta$ release (28). So far, studies had only examined mixed glial cells and there is no study focusing on the immunoregulatory effects of PYNOD specifically in microglia. Whether PYNOD suppresses microglia activation under inflammatory conditions remains unknown.

Therefore, this study aimed to explore how PYNOD regulates the inflammatory signaling in microglia upon lipopolysaccharides (LPS) stimulation and how it affects microglia-induced neurotoxicity, using BV-2 cell line (raf/myc-immortalised murine neonatal microglia) as a substitute for primary microglia (29) and human neuroblastoma cell line SK-N-SH for neuronal cells (30).

\section{Materials and methods}

Cell culture and grouping. Murine microglial cell line BV-2 and human neuroblastoma cell line SK-N-SH were obtained from the Chinese Academy of Sciences (Beijing, China) and cultured in Dulbecco's modified Eagle's medium, containing $10 \%$ fetal bovine serum (FBS), $100 \mathrm{U} / \mathrm{ml}$ penicillin, and $100 \mathrm{U} / \mathrm{ml}$ streptomycin (all from Gibco; Thermo Fisher Scientific, Inc., Waltham, MA, USA), at $37^{\circ} \mathrm{C}$ in a humid environment containing $5 \% \mathrm{CO}_{2}$.

BV-2 cells cultured in $24-$ well plates $\left(6 \times 10^{4}\right.$ cells $\left./ \mathrm{ml}\right)$ or on glass coverslips (for immunofluorescent staining) were subjected to transfection of pEGFP-C2-PYNOD $(0,0.5,2.5$, and $5.0 \mu \mathrm{g} / \mathrm{ml}$; Takara Biotechnology Co., Ltd., Dalian, China) for $24 \mathrm{~h}$, followed by incubation with or without LPS $(1 \mu \mathrm{g} / \mathrm{ml}$; Sigma-Aldrich, St. Louis, MO, USA) for another $24 \mathrm{~h}$; the only exception was that to detect the protein expression and distribution of NF-kB p65, only $1 \mathrm{~h}$ was taken for LPS treatment). Then cell viability was determined; the levels of NO, IL-1 $\beta$ and caspase-1 in supernatant of cell culture were measured; and the protein expressions of NF-кB p65 and iNOS were detected by immunofluorescent staining and/or western blot analysis.

And a co-culture in transwell plates was performed to assess the effects of microglia on neuronal cells in vitro, according to a previous study (31). BV-2 cells were grown in culture inserts and were subjected to transfection of pEGFP-C2-PYNOD $(0$ or $5.0 \mu \mathrm{g} / \mathrm{ml})$ for $24 \mathrm{~h}$, followed by incubation with or without LPS $(1 \mu \mathrm{g} / \mathrm{ml})$ for another $24 \mathrm{~h}$. SK-N-SH cells were then added into the wells. The co-culture lasted for $24 \mathrm{~h}$. Then cell viability and apoptosis of SK-N-SH cells were determined after co-culture.

Cell viability. Cell viability was quantified using the 3-(4,5-dimethylthiazol-2-yl)-2,5-diphenyl tetrazolium bromide (MTT) assay. After removal of the medium, $0.5 \mathrm{mg} / \mathrm{ml}$ of MTT solution in medium was added for $3 \mathrm{~h}$. Then, the supernatants were carefully aspirated, and formazan crystals were dissolved with DMSO; absorbance was measured at $540 \mathrm{~nm}$.

Analysis of cell apoptosis using flow cytometry. Detection of apoptotic cells was performed using the terminal deoxynucleotidyl transferase-mediated dUTP nick end labeling (TUNEL) assay using an Annexin V-FITC/PI apoptosis detection kit (Invitrogen; Thermo Fisher Scientific, Inc.), according to the manufacturer's protocol. Briefly, cells were incubated with fluorescein isothiocyanate (FITC)-conjugated Annexin V and propidium iodide (PI) for $15 \mathrm{~min}$ at $4^{\circ} \mathrm{C}$ in the dark. Cell cycle distribution was quantified by flow cytometry.

NO level measurement. The supernatant of BV-2 cell culture was obtained, and $\mathrm{NO}$ amounts were determined by the Griess method. The supernatants were added with equal amounts of Griess reagent (Promega Corporation, Madison, WI, USA) and kept at room temperature for $10 \mathrm{~min}$. Optical density was measured at $540 \mathrm{~nm}$. A standard curve was obtained with sodium nitrite at 10-100 M.

Enzyme-linked immunosorbent assay (ELISA). The supernatant of BV-2 cell culture was obtained, and IL-1 $\beta$ (cat. no. PMLB00C; R\&D Systems, Inc., Minneapolis, MN, USA) and caspase-1 (cat. no. K111-25; BioVision, Inc., Milpitas, CA, USA) amounts were measured by specific ELISA kits according to the manufacturer's instructions. Optical density was measured at $450 \mathrm{~nm}$. According to the manufacturer, the IL-1 $\beta$ kit had a sensitivity of $2.31 \mathrm{pg} / \mathrm{ml}$, an intra-assay coefficient of variation $(\mathrm{CV})$ of $3.0-7.5 \%$ and an inter-assay $\mathrm{CV}$ of $5.7-8.4 \%$.

Immunofluorescent staining. BV-2 cells were fixed with 3.7\% paraformaldehyde. After permeabilization ( $0.2 \%$ Triton X-100) and blocking ( $2 \%$ bovine serum albumin; Sigma-Aldrich), the samples were treated with rabbit polyclonal anti-NF- $\kappa$ B p65 primary antibodies (1:1,000; Santa Cruz Biotechnology, Inc., Dallas, TX, USA) and Cy5-labelled goat anti-rabbit secondary antibodies (1:5,000; Sigma-Aldrich). The co-staining of nucleus by Hoechst 33258 was performed. Analysis was carried out under a laser scanning confocal microscope (Carl Zeiss AG, Oberkochen, Germany).

Western blot analysis. Cytoplasmic and nuclear proteins were extracted with NE-PER ${ }^{\mathrm{TM}}$ nuclear and cytoplasmic extraction reagents (Thermo Fisher Scientific, Inc.). The BV-2 cells were lysed with radioimmunoprecipitation assay (RIPA) buffer (Thermo Fisher Scientific, Inc.), according to the manufacturer's instructions. Total protein amounts were determined. Electrophoresis was performed with $25 \mu \mathrm{g}$ of proteins loaded in each lane, followed by electro-transfer onto polyvinylidene difluoride (PVDF) membranes. After blocking in 5\% nonfat milk in Tris-buffered saline (TBS) $/ 0.1 \%$ Tween-20, the samples were incubated with primary antibodies (rabbit anti-mouse iNOS, p65, and GAPDH polyclonal antibodies; all at 1:1,000) overnight at $4^{\circ} \mathrm{C}$ in blocking buffer. After thorough washing with phosphate buffered saline Tween-20 
(PBST), horseradish peroxidase (HRP)-conjugated secondary goat anti-mouse antibodies (Cell Signaling Technology, Inc., Danvers, MA, USA) were added for $1 \mathrm{~h}$ at room temperature. Immunoreaction was detected using an enhanced chemiluminescence detection system. The amounts of objective proteins were normalized to that of GAPDH.

Statistical analysis. All statistical analyses were performed using SPSS 13.0 (SPSS, Inc., Chicago, IL, USA). The normal distribution of the data was tested using the KolmogorovSmirnov test and all data were found to be normally distributed. Data were presented as mean \pm standard deviation of three independent experiments. Statistical analysis was done using one-way analysis of variance followed by Tukey's post hoc test. $\mathrm{P}<0.05$ indicated statistically significant differences.

\section{Results}

PYNOD concentration-dependently decreases NO production without cytotoxicity in BV-2 microglial cells upon LPS stimulation. To explore how PYNOD affects the NO production in microglia under inflammatory conditions, BV-2 cells were overexpressed with pEGFP-C2-PYNOD plasmid, followed by LPS stimulation. PYNOD concentration-dependently reduced the NO secretion from BV-2 cells induced by LPS, with statistically significant differences (both $\mathrm{P}<0.05$; Fig. 1A). Furthermore, it was found that LPS stimulation increased the iNOS protein expression in BV-2 cells, which could be suppressed by PYNOD-overexpression, also in a dose-dependent manner (both $\mathrm{P}<0.05$; Fig. 2). Whether such inhibitory effect of PYNOD resulted from cytotoxicity was then examined. PYNOD-overexpression lead to no changes in the growth of BV-2 cells (Fig. 1B), suggesting that PYNOD reduced the NO production independently of cytotoxicity in BV-2 microglial cells upon LPS stimulation.

PYNOD concentration-dependently reduces the secretion of $I L-1 \beta$ and caspase- 1 from BV-2 microglial cells upon LPS stimulation. IL-1 $\beta$ secretion from BV-2 microglial cells was significantly higher $(551.5 \mathrm{pg} / \mathrm{ml})$ after LPS stimulation $(\mathrm{P}<0.05$, Fig. 3A); however, the increase of IL-1 $\beta$ secretion was inhibited by PYNOD overexpression (both $\mathrm{P}<0.05$, Fig. $3 \mathrm{~A}$ ), declining to $340.6 \mathrm{pg} / \mathrm{ml}(2.5 \mu \mathrm{g} / \mathrm{ml}$ pEGFP-C2-PYNOD transfection) or $250.3 \mathrm{pg} / \mathrm{ml}(5.0 \mu \mathrm{g} / \mathrm{ml} \mathrm{pEGFP-C2-PYNOD} \mathrm{transfection).}$ Caspase-1 amount in the supernatant of BV-2 cell culture was 7.62-fold higher after LPS stimulation ( $\mathrm{P}<0.05$; Fig. 3B), while it was significantly suppressed by PYNOD overexpression to lower level, about 5.47-fold or 3.32-fold of the un-stimulated control (2.5 or $5.0 \mu \mathrm{g} / \mathrm{ml} \mathrm{pEGFP-C2-PYNOD} \mathrm{transfection)}$ (both $\mathrm{P}<0.05$; Fig. 3B).

$P Y N O D$ prevent the nuclear translocation of $N F-\kappa B$ in $B V-2$ microglial cells upon LPS stimulation. The protein amount of NF- $\kappa$ B p65 in nucleus of BV-2 cells was high after LPS stimulation (Fig. 4A), which was significantly decreased by PYNOD overexpression $(\mathrm{P}<0.05$; Fig. 4A). And immunofluorescent staining confirmed that the intracellular distribution of NF- $\mathrm{\kappa B}$ p65 was restricted in nuclear or perinuclear regions (Fig. 4B); however, PYNOD overexpression resulted in cytoplasmic distribution of NF-kB p65. The results suggested that PYNOD
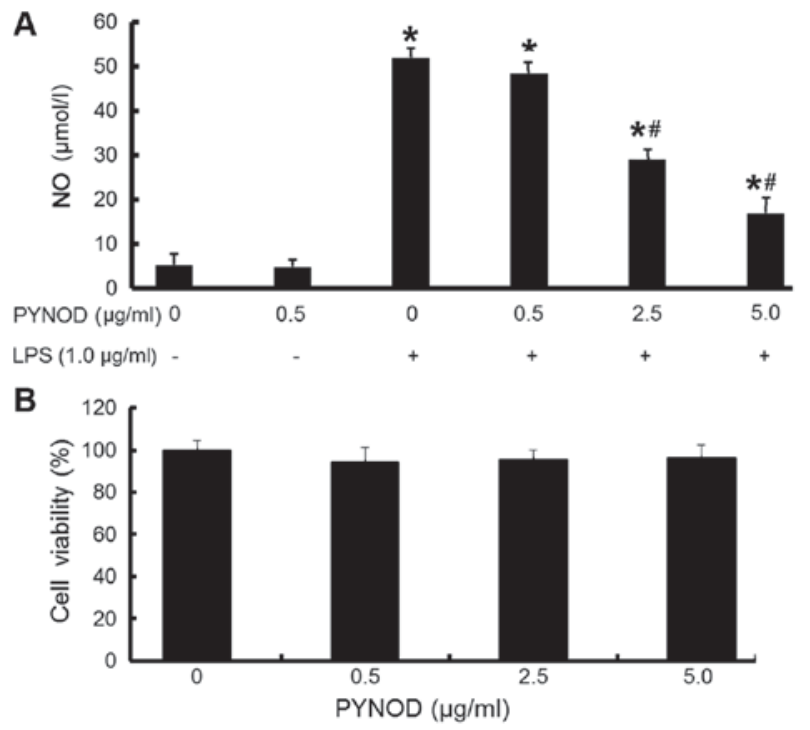

Figure 1. PYNOD decreases NO secretion in LPS-stimulated BV-2 microglial cells in a concentration-dependent manner. (A) Murine microglial cell line BV-2 were transfected with pEGFP-C2-PYNOD $(0,0.5,2.5$ and $5.0 \mu \mathrm{g} / \mathrm{ml})$ for $24 \mathrm{~h}$ and then subjected to LPS treatment $(1.0 \mu \mathrm{g} / \mathrm{ml})$ for another $24 \mathrm{~h}$. NO level in the supernatant of cell culture was measured using the Griess method. (B) BV-2 cells were transfected with pEGFP-C2-PYNOD $(0,0.5$, 2.5 and $5.0 \mu \mathrm{g} / \mathrm{ml}$ ) for $24 \mathrm{~h}$. Cell viability was determined using MTT assay. The results were expressed as mean \pm standard deviation of three independent experiments. ${ }^{*} \mathrm{P}<0.05$, compared with the un-stimulated control group; ${ }^{\#} \mathrm{P}<0.05$, compared with the LPS treatment plus no transfection group. NO, nitric oxide; LPS, lipopolysaccharides.

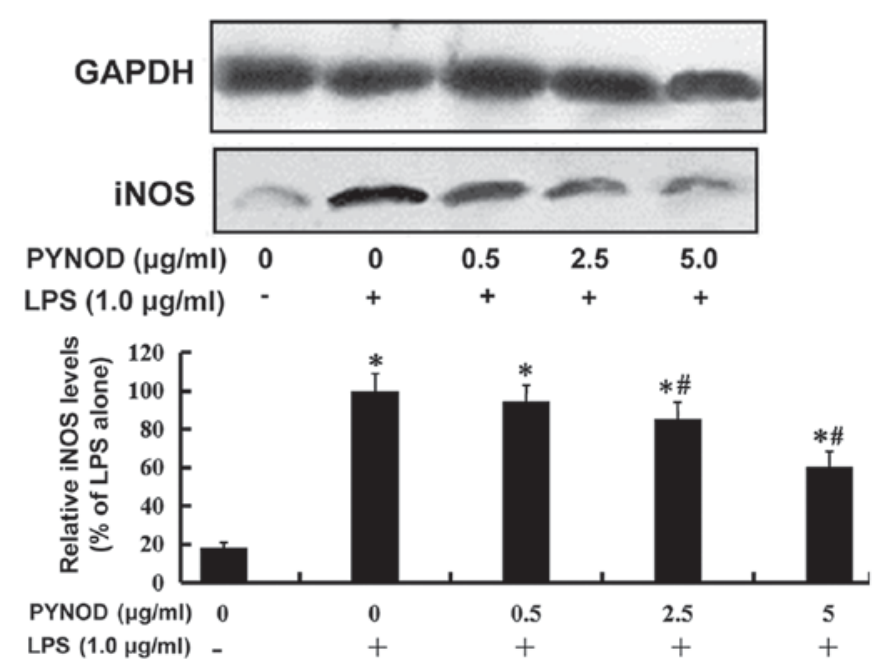

Figure 2. PYNOD decreases the protein expression of iNOS in LPS-stimulated BV-2 microglial cells in a concentration-dependent manner. BV-2 cells were transfected with pEGFP-C2-PYNOD $(0,0.5,2.5$ and $5.0 \mu \mathrm{g} / \mathrm{ml})$ for $24 \mathrm{~h}$ and then subjected to LPS treatment $(1.0 \mu \mathrm{g} / \mathrm{ml})$ for another $24 \mathrm{~h} .25 \mu \mathrm{g}$ total protein extracted from the cells was subjected to western blot analysis. Relative protein expression of iNOS in each group was quantified with GAPDH as the internal control. The results were expressed as mean \pm standard deviation of three independent experiments, and normalized to the LPS treatment plus no transfection group. ${ }^{*} \mathrm{P}<0.05$, compared with the un-stimulated control group; ${ }^{\#} \mathrm{P}<0.05$, compared with the LPS treatment plus no transfection group. iNOS, inducible nitric oxide synthase; LPS, lipopolysaccharides.

might prevent the nuclear translocation of NF- $\mathrm{BB}$ p 65 in BV-2 cells upon LPS stimulation, thus inhibiting the generation of inflammatory singling. 
A

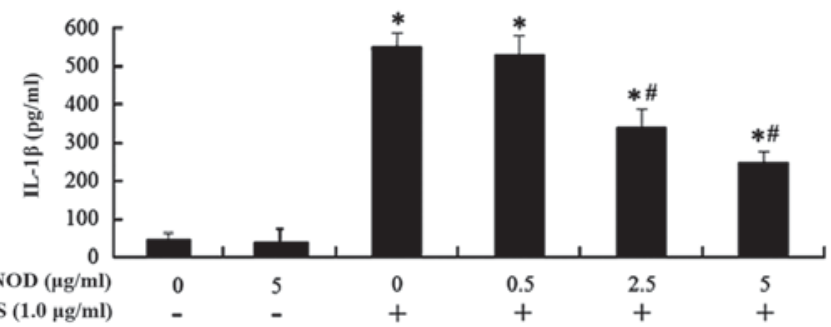

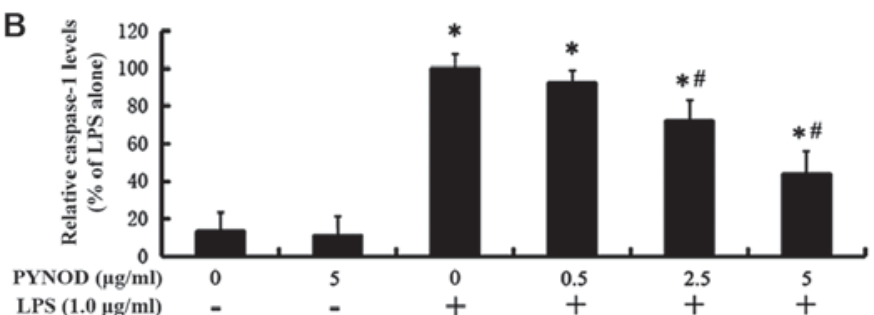

Figure 3. PYNOD reduces the secretion of IL-1 $\beta$ and caspase-1 in LPS-stimulated BV-2 microglial cells in a concentration-dependent manner. BV-2 cells were transfected with pEGFP-C2-PYNOD $(0,0.5,2.5$ and $5.0 \mu \mathrm{g} / \mathrm{ml})$ for $24 \mathrm{~h}$ and then subjected to LPS treatment $(1.0 \mu \mathrm{g} / \mathrm{ml})$ for another $24 \mathrm{~h}$. The supernatant of cell culture was assessed for (A) IL-1 $\beta$ and (B) caspase-1 amounts. The results were expressed as mean \pm standard deviation of three independent experiments, and the results in (B) were normalized to the LPS treatment plus no transfection group. ${ }^{*} \mathrm{P}<0.05$, compared with the un-stimulated control group; ${ }^{*} \mathrm{P}<0.05$, compared with the LPS treatment plus no transfection group. IL, interleukin; LPS, lipopolysaccharides.

A

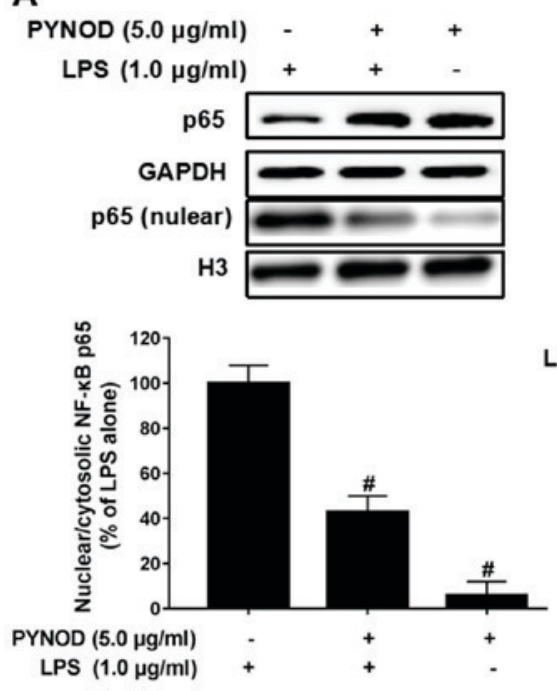

B

p65 Hochest Hochest Merge

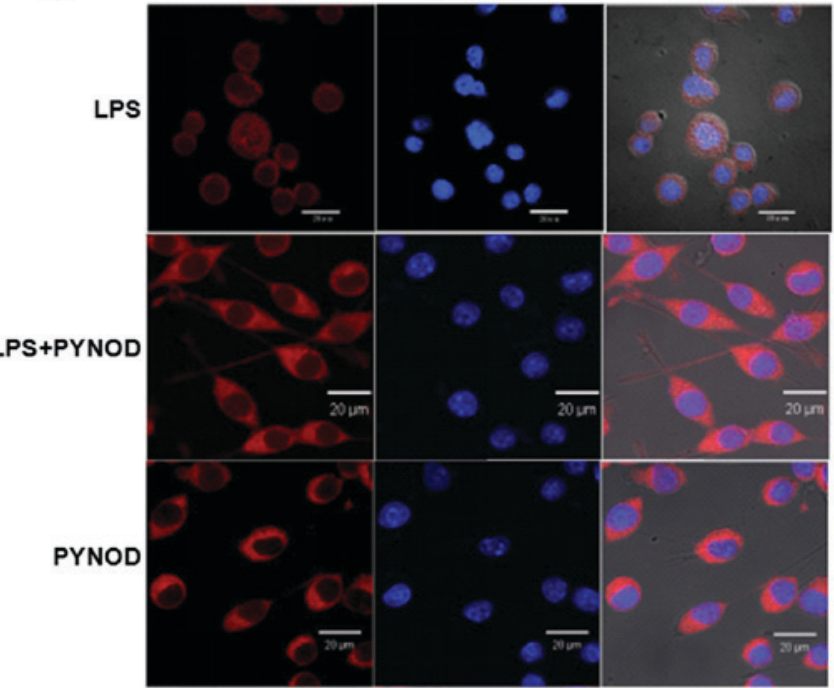

Figure 4. PYNOD prevents the nuclear translocation of NF- $\mathrm{B}$ in LPS-stimulated BV-2 microglial cells. BV-2 cells were transfected with pEGFP-C2-PYNOD $(0,0.5,2.5$ and $5.0 \mu \mathrm{g} / \mathrm{ml})$ for $24 \mathrm{~h}$ and then subjected to LPS treatment $(1.0 \mu \mathrm{g} / \mathrm{ml})$ for another $1 \mathrm{~h}$. (A) Nuclear protein and cytosolic protein were respectively extracted from the cells, and assessed by western blot for NF-кB p65 detection; GAPDH was used as an internal control. (B) Immunofluorescent staining was performed to detect the cellular distribution of NF- $\mathrm{BB}$ p65 (red). Hoechst 33258 (blue) was used to stain the nuclei. Scale bar, $20 \mu \mathrm{m}$. The results were expressed as mean \pm standard deviation of three independent experiments, and the results in (A) were normalized to the LPS treatment plus no transfection group. ${ }^{\#} \mathrm{P}<0.05$, compared with the LPS treatment plus no transfection group. LPS, lipopolysaccharides.

PYNOD alleviated the neurotoxic effects of microglia upon LPS stimulation. There was a decrease of cell viability $(\mathrm{P}<0.05$; Fig. 5A) and an increase of apoptosis $(\mathrm{P}<0.05$; Fig. 5B) in human neuroblastoma SK-N-SH cells when the co-cultured BV-2 cells had been subjected to LPS stimulation. However, these changes in SK-N-SH cells were significantly alleviated (both $\mathrm{P}<0.05$; Fig. 5A and B) if the co-cultured BV-2 cells had been overexpressed with PYNOD before LPS stimulation. Notably, PYNOD overexpression in BV-2 cells without LPS stimulation would never affect the cell viability or cell apoptosis of co-cultured SK-N-SH cells.

\section{Discussion}

This study aimed to explore the roles of PYNOD involved in the LPS-induced microglial inflammation and consequent neurotoxicity. The results showed that PYNOD overexpression inhibited NO release and iNOS protein expression induced by LPS in BV-2 cells, independently of cytotoxicity. It also reduced the secretion of IL-1 $\beta$ and caspase- 1 from BV-2 cells upon
LPS stimulation. The effects were dose-dependent. PYNOD overexpression prevented LPS-induced nuclear translocation of NF- $\mathrm{NB}$ p65 in BV-2 cells. The growth-inhibitory and apoptosis-promoting effects of BV-2 cells towards SK-N-SH cells were alleviated as a result of PYNOD overexpression.

Increased amounts of NO produced by iNOS in induced microglia are considered to be cytotoxic in CNS inflammation, and related to neurodegenerative disease etiology (32). Indeed, agents inhibiting iNOS expression carry potential benefits in the treatment of high-NO-related inflammatory disorders (33). Pro-inflammatory cytokines, like IL-1 $\beta$, are produced in large amounts by microglia after stimulation by molecules such as IFN- $\gamma$ and LPS during the inflammatory process, constituting potential factors causing neurological diseases (34). Caspase-1 is known to cleave pro-IL-1 $\beta$ for activation, a process critical to IL-1 $\beta$ secretion. A previous study showed in that treating mixed glial cells with recombinant PYNOD led to reduced caspase- 1 activation and IL-1 $\beta$ secretion (28). The present study was carried out using microglial cells (which are included among the mixed glial cells) and 


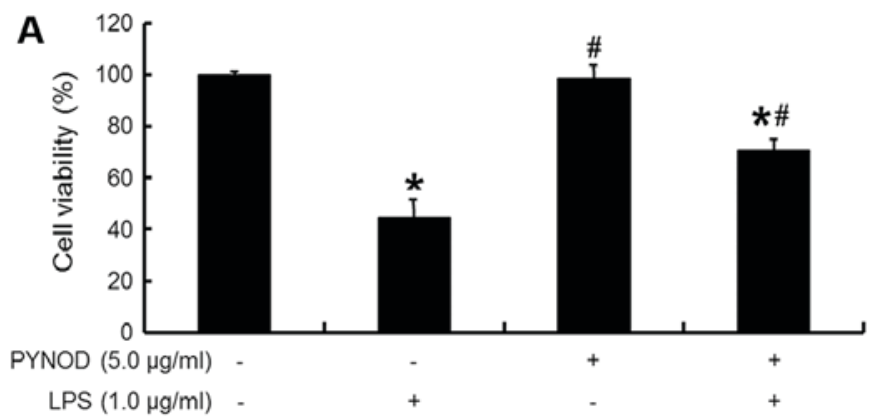

B
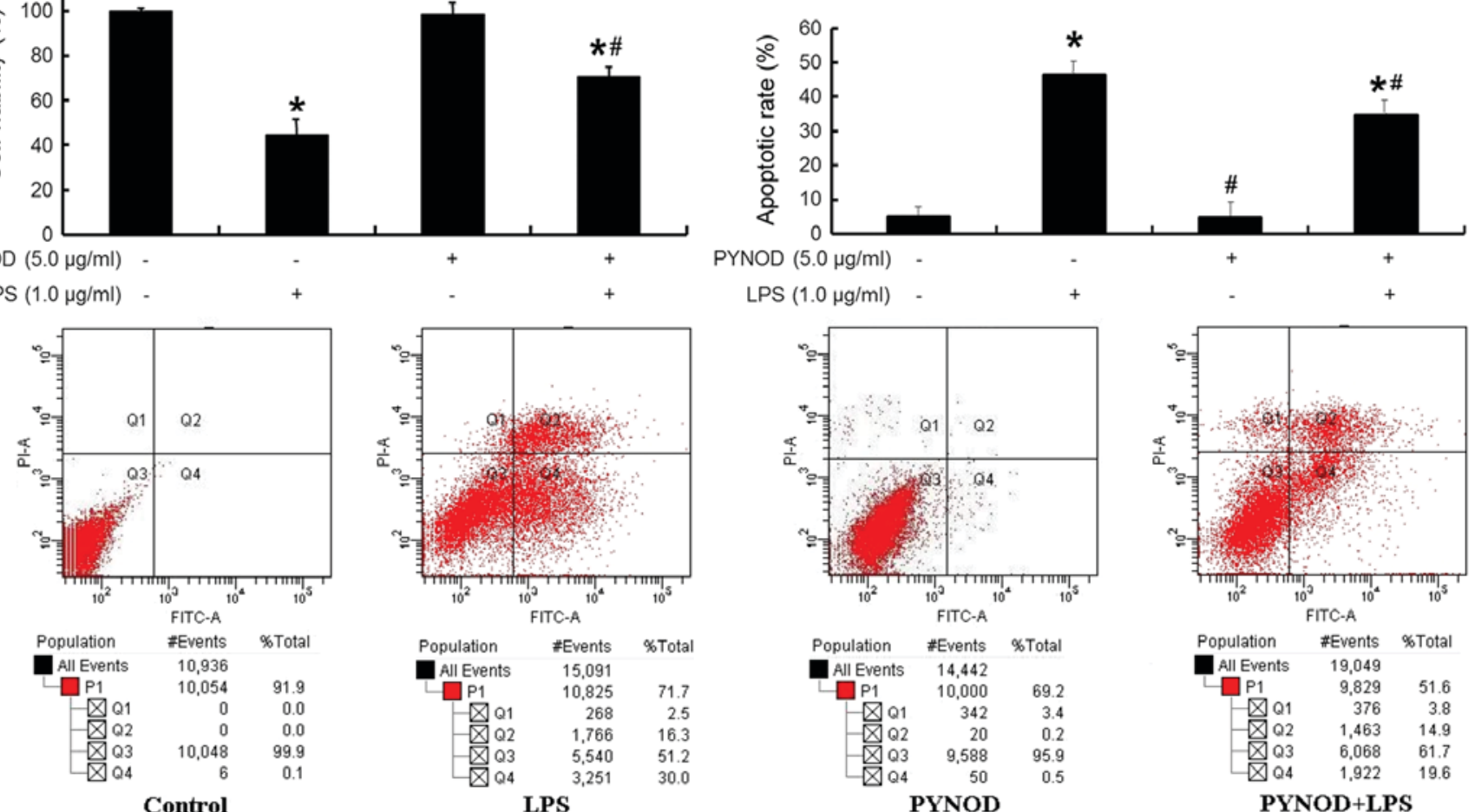

Figure 5. PYNOD alleviated the neurotoxic effects of microglia upon LPS stimulation. A co-culture assay in Transwell plates was performed: BV-2 cells were subjected to transfection of pEGFP-C2-PYNOD $(0$ or $5.0 \mu \mathrm{g} / \mathrm{ml})$ for $24 \mathrm{~h}$, followed by incubation with or without LPS $(1 \mu \mathrm{g} / \mathrm{ml})$ for another $24 \mathrm{~h}$. Then the human neuroblastoma cell line SK-N-SH was added for $24 \mathrm{~h}$ co-culture. (A) Viability of SK-N-SH cells was determined by the MTT assay. (B) Apoptosis level of SK-N-SH cells was determined by flow cytometry. The results were expressed as mean \pm standard deviation of three independent experiments. "P $<0.05$, compared with the un-stimulated control group; ${ }^{*} \mathrm{P}<0.05$, compared with the LPS treatment plus no transfection group. LPS, lipopolysaccharides.

showed that PYNOD reduced LPS-induced production of IL-1 $\beta$ and caspase-1 in a dose-dependent manner. The present study implied that PYNOD modulates the secretion of the pro-inflammatory cytokine IL-1 $\beta$ after microglia activation through caspase-1 inhibition.

$\mathrm{NF}-\mathrm{kB}$ plays key roles in multiple pathologies and represents a main drug target for various diseases $(35,36)$. The promoter region of the mouse gene encoding iNOS harbors an NF- $\kappa \mathrm{B}$ binding site, and NF- $\mathrm{KB}$ induction is key in NO and iNOS production in LPS-stimulated microglia (37). As shown above, PYNOD prevented the nuclear translocation of LPS-stimulated p65 in LPS-treated BV-2 microglial cells, revealing a potential role for NF- $\kappa B$ in PYNOD's suppressive effects on inflammatory effectors such as NO and IL-1

Microglial activation is deleterious to neurons, causing apoptosis (19). Neurotoxic microglial-neuronal interactions are considered to be important in the development of neurological diseases (38). Our results showed that neurons co-cultured with LPS-treated BV-2 microglial cells showed enhanced cell death and apoptosis. Nevertheless, transfection with PYNOD in LPS-stimulated co-cultures resulted in higher cell viability and less apoptotic cells. These results suggested a beneficial effect of PYNOD on microglia neurotoxicity in co-cultures. Thus, neuroprotection by PYNOD might result from its effects on microglia. Nevertheless, other cells in the brain may also be affected by PYNOD. Indeed, PYNOD is expressed in neurons and its expression is increased in injured neurons (39). NLRs (including PYNOD) play important roles in the cerebral endothelial cells and the maintenance of the brain-blood barrier under immune and inflammatory processes (40). NLRs (again including PYNOD) also play roles in the non-canonical inflammasone activation in pericytes (41). Taken together, these results strongly suggest that PYNOD is involved in the neuroinflammatory process of many cell types in the CNS. Additional studies are necessary to determine its exact roles in the brain and how these different cell types interact together in neuroinflammation. However this protein was recently discovered and none of the inhibitors against it, so activators/inhibitors of downstream signalling molecules (such as IL-1 $\beta$, NF- $\mathrm{kB}$ ) will need to be demonstrate the specific effects of PYNOD. In addition, knock-out models and PYNOD-transgenic mice will be necessary to delineate the exact roles of PYNOD.

Taken together, the present study revealed that PYNOD could mitigate microglial inflammation and consequent neurotoxicity. Therefore, PYNOD might be therapeutically used as an anti-inflammatory drug target suppressing excessive microglia activation associated with exacerbated neuronal cell death under brain injury conditions.

\section{Acknowledgements}

Not applicable.

\section{Funding}

The present study was supported by grants from the National Natural Science Foundation of China (grant 
no. 81441046), Science Foundation of Jiangxi Province (grant no. 20142BAB215055), and Science and Technology Commission of Jiangxi Province Health Department (grant no. 20143124).

\section{Availability of data and materials}

The datasets used and/or analyzed during the current study are available from the corresponding author on reasonable request.

\section{Authors' contributions}

QZ contributed to the study design, data acquisition and analysis and drafted the manuscript; $\mathrm{CH}$ was involved in data acquisition and revision of the manuscript; RQ was involved in data acquisition and analysis; DL worked on aspects of the study design, data acquisition and analysis and revised the manuscript.

\section{Ethics approval and consent to participate}

Not applicable.

\section{Consent for publication}

Not applicable.

\section{Conflict of interests}

The authors declare that they have no competing interests.

\section{References}

1. Pérez-FigueroaE,Torres J,Sánchez-ZaucoN,Contreras-Ramos A, Alvarez-Arellano L and Maldonado-Bernal C: Activation of NLRP3 inflammasome in human neutrophils by Helicobacter pylori infection. Innate Immun 22: 103-112, 2016.

2. Zambetti LP, Laudisi F, Licandro G, Ricciardi-Castagnoli P and Mortellaro A: The rhapsody of NLRPs: Master players of inflammation...and a lot more. Immunol Res 53: 78-90, 2012.

3. Caruso R, Warner N, Inohara N and Núñez G: NOD1 and NOD2: Signaling, host defense and inflammatory disease. Immunity 41 : 898-908, 2014

4. Chavarría-Smith J and Vance RE: The NLRP1 inflammasomes. Immunol Rev 265: 22-34, 2015.

5. Garbarino-Pico E, Niu S, Rollag MD, Strayer CA, Besharse JC and Green CB: Immediate early response of the circadian polyA ribonuclease nocturnin to two extracellular stimuli. RNA 13: $745-755,2007$.

6. Kinoshita T, Wang Y, Hasegawa M, Imamura R and Suda T: PYPAF3, a PYRIN-containing APAF-1-like protein, is a feedback regulator of caspase-1-dependent interleukin-1beta secretion. J Biol Chem 280: 21720-21725, 2005.

7. Zeng Q, Lu D, Tang Q, Tian L, Wang H, Tang S and Hu C: Functional characterization of the p53 binding site in the human PYNOD promoter. Hum Immunol 73: 355-363, 2012.

8. Wang Y, Hasegawa M, Imamura R, Kinoshita T, Kondo C, Konaka K and Suda T: PYNOD, a novel Apaf-1/CED4-like protein is an inhibitor of ASC and caspase-1. Int Immunol 16 777-786, 2004

9. Imamura R, Wang Y, Kinoshita T, Suzuki M, Noda T, Sagara J, Taniguchi S, Okamoto H and Suda T: Anti-inflammatory activity of PYNOD and its mechanism in humans and mice. J Immunol 184: 5874-5884, 2010.

10. Eisenbarth SC, Williams A, Colegio OR, Meng H, Strowig T, Rongvaux A, Henao-Mejia J, Thaiss CA, Joly S, Gonzalez DG, et al: NLRP10 is a NOD-like receptor essential to initiate adaptive immunity by dendritic cells. Nature 484: 510-513, 2012.

11. Liu D, Rhebergen AM and Eisenbarth SC: Licensing adaptive immunity by NOD-like receptors. Front Immunol 4: 486, 2013.
12. Krishnaswamy JK, Singh A, Gowthaman U, Wu R, Gorrepati P, Sales Nascimento M, Gallman A, Liu D, Rhebergen AM, Calabro S, et al: Coincidental loss of DOCK8 function in NLRP10-deficient and $\mathrm{C} 3 \mathrm{H} / \mathrm{HeJ}$ mice results in defective dendritic cell migration. Proc Natl Acad Sci USA 112: 3056-3061, 2015.

13. Vacca M, Böhme J, Zambetti LP, Khameneh HJ, Paleja BS, Laudisi F, Ho AWS, Neo K, Leong KWK, Marzuki M, et al: NLRP10 enhances CD4 ${ }^{+}$T-cell-mediated IFN $\gamma$ response via regulation of dendritic cell-derived IL-12 release. Front Immunol 8: $1462,2017$.

14. Imai K, Kotani T, Tsuda H, Mano Y, Nakano T, Ushida T, Li H, Miki R, Sumigama S, Iwase A, et al: Neuroprotective potential of molecular hydrogen against perinatal brain injury via suppression of activated microglia. Free Radic Biol Med 91: 154-163, 2016.

15. Zindler E and Zipp F: Neuronal injury in chronic CNS inflammation. Best Pract Res Clin Anaesthesiol 24: 551-562, 2010.

16. Baby N, Patnala R, Ling EA and Dheen ST: Nanomedicine and its application in treatment of microglia-mediated neuroinflammation. Curr Med Chem 21: 4215-4226, 2014.

17. Yang LL, Zhou Y, Tian WD, Li HJ, Kang-Chu-Li, Miao X, An GZ, Wang XW, Guo GZ and Ding GR: Electromagnetic pulse activated brain microglia via the p38 MAPK pathway. Neurotoxicology 52: 144-149, 2016.

18. Papageorgiou IE, Lewen A, Galow LV, Cesetti T, Scheffel J, Regen T, Hanisch UK and Kann O: TLR4-activated microglia require IFN- $\gamma$ to induce severe neuronal dysfunction and death in situ. Proc Natl Acad Sci USA 113: 212-217, 2016.

19. Gu Y, Yang DK, Spinas E, Kritas SK, Saggini A, Caraffa A, Antinolfi P, Saggini R and Conti P: Role of TNF in mast cell neuroinflammation and pain. J Biol Regul Homeost Agents 29: 787-791, 2015.

20. Shih RH, Wang CY and Yang CM: NF-kappaB signaling pathways in neurological inflammation: A mini review. Front Mol Neurosci 8: 77, 2015.

21. Frakes AE, Ferraiuolo L, Haidet-Phillips AM, Schmelzer L, Braun L, Miranda CJ, Ladner KJ, Bevan AK, Foust KD, Godbout JP, et al: Microglia induce motor neuron death via the classical NF- $\kappa \mathrm{B}$ pathway in amyotrophic lateral sclerosis. Neuron 81: 1009-1023, 2014.

22. Owens R, Grabert K, Davies CL, Alfieri A, Antel JP, Healy LM and McColl BW: Divergent neuroinflammatory regulation of microglial TREM expression and involvement of NF- $\mathrm{KB}$. Front Cell Neurosci 11: 56, 2017.

23. Xiong JY, Li SC, Sun YX, Zhang XS, Dong ZZ, Zhong P and Sun XR: Long-term treadmill exercise improves spatial memory of male APPswe/PS1dE9 mice by regulation of BDNF expression and microglia activation. Biol Sport 32: 295-300, 2015.

24. Li JY, Ma SS, Huang QY and Li MT: The function of neuroinflammation in parkinson disease. Sheng Li Ke Xue Jin Zhan 46: 175-179, 2015 (In Chinese).

25. Rangarajan P, Karthikeyan A, Lu J, Ling EA and Dheen ST: Sirtuin 3 regulates Foxo3a-mediated antioxidant pathway in microglia. Neuroscience 311: 398-414, 2015.

26. Gravel M, Béland LC, Soucy G, Abdelhamid E, Rahimian R, Gravel C and Kriz J: IL-10 controls early microglial phenotypes and disease onset in ALS caused by misfolded superoxide dismutase 1. J Neurosci 36: 1031-1048, 2016.

27. Gendelman HE and Mosley RL: A perspective on roles played by innate and adaptive immunity in the pathobiology of neurodegenerative disorders. J Neuroimmune Pharmacol 10: 645-650, 2015.

28. Murphy N, Grehan B and Lynch MA: Glial uptake of amyloid beta induces NLRP3 inflammasome formation via cathepsin-dependent degradation of NLRP10. Neuromolecular Med 16: 205-215, 2014.

29. Henn A, Lund S, Hedtjärn M, Schrattenholz A, Pörzgen P and Leist M: The suitability of BV2 cells as alternative model system for primary microglia cultures or for animal experiments examining brain inflammation. ALTEX 26: 83-94, 2009.

30. Blasko I, Apochal A, Boeck G, Hartmann T, GrubeckLoebenstein B and Ransmayr G: Ibuprofen decreases cytokineinduced amyloid beta production in neuronal cells. Neurobiol Dis 8: 1094-1101, 2001.

31. Kiyota T, Ingraham KL, Swan RJ, Jacobsen MT, Andrews SJ and Ikezu T: AAV serotype 2/1-mediated gene delivery of anti-inflammatory interleukin-10 enhances neurogenesis and cognitive function in APP+PS1 mice. Gene Ther 19: 724-733, 2012.

32. White PA, Oliveira RC, Oliveira AP, Serafini MR, Araújo AA, Gelain DP, Moreira JC, Almeida JR, Quintans JS, QuintansJunior LJ and Santos MR: Antioxidant activity and mechanisms of action of natural compounds isolated from lichens: A systematic review. Molecules 19: 14496-14527, 2014. 
33. McCarthy RC, Lu DY, Alkhateeb A, Gardeck AM, Lee CH and Wessling-Resnick $\mathrm{M}$ : Characterization of a novel adult murine immortalized microglial cell line and its activation by amyloid-beta. J Neuroinflammation 13: 21, 2016.

34. Wang WY, Tan MS, Yu JT and Tan L: Role of pro-inflammatory cytokines released from microglia in Alzheimer's disease. Ann Transl Med 3: 136, 2015.

35. Muriel P: NF-kappaB in liver diseases: A target for drug therapy. J Appl Toxicol 29: 91-100, 2009.

36. Yu L, Li L, Medeiros LJ and Young KH: NF- $\kappa$ B signaling pathway and its potential as a target for therapy in lymphoid neoplasms. Blood Rev 31: 77-92, 2017.

37. Abbasi Habashi S, Sabouni F, Moghimi A and Ansari Majd S: Modulation of lipopolysaccharide stimulated nuclear factor kappa B mediated iNOS/NO production by bromelain in rat primary microglial cells. Iran Biomed J 20: 33-40, 2016.

38. Bi W, Zhu L, Jing X, Zeng Z, Liang Y, Xu A, Liu J, Xiao S, Yang L, Shi Q, et al: Rifampicin improves neuronal apoptosis in LPS-stimulated co-cultured BV2 cells through inhibition of the TLR-4 pathway. Mol Med Rep 10: 1793-1799, 2014.
39. Frederick Lo C, Ning X, Gonzales $C$ and Ozenberger BA: Induced expression of death domain genes NALP1 and NALP5 following neuronal injury. Biochem Biophys Res Commun 366: 664-669, 2008

40. Nagyőszi P, Nyúl-Tóth Á, Fazakas C, Wilhelm I, Kozma M, Molnár J, Haskó J and Krizbai IA: Regulation of NOD-like receptors and inflammasome activation in cerebral endothelial cells. J Neurochem 135: 551-564, 2015.

41. Nyúl-Tóth Á, Kozma M, Nagyőszi P, Nagy K, Fazakas C, Haskó J, Molnár K, Farkas AE, Végh AG, Váró G, et al: Expression of pattern recognition receptors and activation of the non-canonical inflammasome pathway in brain pericytes. Brain Behav Immun 64: 220-231, 2017.

(i) $(-)$ This work is licensed under a Creative Commons Attribution-NonCommercial-NoDerivatives 4.0 International (CC BY-NC-ND 4.0) License. 